\title{
A liderança e coesão grupal no futebol profissional: o pesquisador fora do jogo
}

CDD. 20.ed. 796.011

796.33

Rafael Moreno CASTELLANI*

\section{Resumo}

Este estudo buscou retratar os efeitos da liderança sobre o funcionamento do grupo; detectar a importância e necessidade de um grupo coeso no futebol profissional; descrever/analisar a relação entre o pesquisador e clube; e apontar as limitações e obstáculos enfrentados durante a pesquisa de campo. De cunho qualitativo e com referencial teórico da psicologia social, sobretudo Kurt Lewin e Pichon-Rivière, este estudo partiu da análise de um grupo de futebol profissional. Dentre as dificuldades encontradas destacam-se: impossibilidade de acesso às situações/locais sugeridos metodologicamente; negativas de entrevistas; rejeição da aplicabilidade do teste de livre escolha. Identificou-se a vontade/necessidade do clube em manter ao pesquisador estas limitações. 0 vínculo criado e papéis assumidos prejudicaram ainda mais as análises. A percepção da importância da liderança e da coesão do grupo está presente no futebol profissional tendo a liderança situacional e a democrática maior relevância neste contexto específico.

Unitermos: Pesquisa; Futebol profissional; Grupo; Vinculo; Psicologia social.

\section{Introdução}

Os estudos relacionados ao futebol realizados pelas ciências humanas e sociais, no âmbito da área acadêmica Educação Física, apesar de terem aumentado nos últimos anos, ainda são escassos, principalmente quando comparados aos estudos realizados na área pelas ciências biológicas. Quando o foco passa a ser o futebol profissional, uma série de fatores contribui para agravar ainda mais esse quadro, mas certamente um deles passa pela dificuldade e limitaçóes impostas pelos clubes aos pesquisadores que se propõem a estudar o futebol sob o viés das ciências humanas e sociais.

No campo da psicologia esportiva, alguns trabalhos têm procurado compreender aspectos/fenômenos psicológicos, tal qual a liderança e a coesão grupal, no contexto do futebol. No entanto, raros são aqueles que procuram fazê-lo sob a ótica da psicologia social, visto que a psicologia cognitivocomportamental predomina no meio acadêmico.

O futebol profissional possui características específicas que o distingue das demais modalidades esportivas e o fazem um campo de estudo complexo, de difícil acesso, com diversos aspectos que dificultam a relação entre o pesquisador e o campo (CAstellani, 2010). A mercadorização do futebol, entendida por EsCher e ReIs (2008) como "um processo de transformação em objeto essencialmente de comércio", atrelada à sua globalização, foram responsáveis pela ampliação das transmissóes televisivas e "marketing" esportivo, assim como pela crescente privatização da sua prática, consumo e organização. Tais fatores, assim como alguns outros ainda a serem explicitados neste artigo, possuem papel determinante na configuração desta realidade.

A caracterização do futebol profissional em uma atividade extremamente lucrativa, mercantilizada e politizada que fazem dele um grande negócio, além de ser primordial no tocante à repercursão, apelo social, e interesses despertados traz, por outro lado, particularidades que o distância, por vezes, dos objetivos de uma pesquisa acadêmica. Retratar os efeitos da liderança sobre o funcionamento do grupo e detectar a importância e necessidade de um grupo coeso no futebol profissional foram objetivos deste estudo. Não obstante, procurou-se também descrever e analisar a relação entre o pesquisador (com foco voltado à compreensão dos processos grupais) e o clube de futebol - sobretudo a partir do desenvolvimento do vínculo e desempenho de papéis - e apontar as 
limitaçôes e os obstáculos enfrentados no decorrer da pesquisa de campo. Para tal finalidade, apoiouse no referencial teórico da psicologia social, mais especificamente em Kurt Lewin e Pichon-Rivière, extraindo de tais autores também o suporte metodológico necessário e pertinente ao estudo dos processos grupais de uma equipe profissional de futebol.

Neste aspecto foram de fundamental importância as consideraçôes de Kurt Lewin e Pichon-Rivière. LEWIN (1965, 1973), sobretudo pelos seus estudos referentes aos diversos grupos sociais e à sua teoria de campo social e PiCHON-Rivière (1982, 2000) principalmente pela sua teoria do vínculo e análise dos papéis. Apesar de reconhecer que Pichon-Rivière avança nas consideraçóes de Lewin (relevando o momento histórico de seus estudos), ambos concordam quanto à constatação de que somente a pesquisa realizada no campo pode oferecer condições válidas de experimentação de fenômenos socias, ou seja, o seu objeto de estudo somente pode ser compreendido a partir da investigação da realidade da qual está imerso.

Ainda assim, a opção de ter a psicologia social como norteadora deste estudo foi reforçada pela compreensão de que, assim como afirmam Rivière e Quiroga (1998), a psicologia social, como a mais moderna das ciências do homem, nasceu num campo de futebol, o que retrata o significado social que esta modalidade possui. "Se sua prática é realizada espontaneamente, para orientá-lo completamente, é indispensável fazer dele um estudo sociopsicológico" (Rivitire \& QuirogA, 1998).

As diversas manifestações de liderança, assim como os demais processos grupais são de extrema valia para o futebol, principalmente por ter esta modalidade como uma de suas relevantes características o "espírito de grupo" e a importância do trabalho coletivo. O futebol, por tratar-se de uma modalidade coletiva, exige uma preparação fundamentada em torno do grupo, estabelecendo uma relação coesa assim como uma liderança em seu benefício, com a consequente obtenção de metas. São justamente os aspectos e manifestações de liderança e de coesão grupal que receberam neste estudo maior atenção em busca do entendimento de como se estabelecem e se processam as relações de grupo em uma equipe profissional do futebol brasileiro.

\section{O futebol contemporâneo e a contribuição da psicologia social}

Várias leituras, sob diferentes enfoques teóricos, têm sido realizadas na expectativa de buscar compreender o fenômeno do futebol brasileiro. REBELO e TORRES (2001) retratam bem o que significa atualmente essa prática esportiva que se tornou a mais consumida no planeta (Reis \& Escher, 2006). Para tais autores, o futebol passou a ser cada vez mais elemento de identidade nacional, atividade de massa capaz de envolver milhares de praticantes e torcedores, importante para o aprimoramento esportivo, físico e técnico, e para a formação moral da população. Além disso, tornou-se a maior fonte de lazer para as crianças, jovens e adultos de todo o país, o que retrata seu dinamismo econômico por se caracterizar como "atividade geradora de empregos e criadora de riquezas em volume considerável para o PIB (Produto Interno Bruto) nacional".

Ao longo do seu processo histórico, dois acontecimentos foram cruciais para a configuração do futebol contemporâneo: Sua globalização e sua mercadorização. Como uma das maiores, se não a maior, responsáveis pela característica que tomou conta do futebol atual, a globalização facilitou a ampliação do acesso da população mundial à prática e principalmente ao consumo desta modalidade esportiva. Lovisolo
(2001), ao tratar do futebol globalizado, preocupa-se em expor duas explicações para esse fenômeno: Uma universalista na qual o estilo, as práticas e as organizações esportivas são homogeneizadas de modo a servir à mercadorização desta prática esportiva, ou seja, servir ao modelo de futebol empresarial, à universalização do modelo de futebol-empresa e à lógica irrestrita ao lucro; e outra regionalista que dá conta de reconhecer a diversidade de culturas e das práticas regionais.

Já a mercadorização do futebol, entendida por EsCHER e ReIs (2008) como "um processo de transformação em objeto essencialmente de comércio", se reflete na venda dos direitos de imagem das seleções, dos clubes e jogadores para as empresas, na venda dos direitos de transmissão dos jogos para os diversos meios de comunicação (tv, rádio, internet) assim como nas transferências de jogadores entre clubes (principalmente do exterior). SMIT (2007) ressalta que foi somente nos anos 80 do século passado que a sua mercantilização passou a ganhar força, pois ganhava espaço nesse contexto o futebol-empresa e o "marketing" esportivo. REIS (2003) acrescentaria que esse momento histórico se configurou como um marco que fez do futebol "a mercadoria mais rentável na indústria do lazer”. 
Assim, o futebol contemporâneo é visto, portanto, não mais somente como uma prática social, modernizada, globalizada, produtora de identidade nacional, mas também e principalmente como um espaço político e econômico extremamente rentável.

Neste contexto, no qual a busca incessante pelas vitórias é marcada por um conjunto de interesses que ultrapassam os limites do campo de jogo, a pressão "despejada" sobre o clube e atletas tem sido cada vez maior. Diante disso, passa a ser cada vez mais frequente que as grandes equipes, apesar de possuidoras de uma boa estrutura física e organizacional (com comissões técnicas e plantel de jogadores de extrema qualidade), apresentem resultados muito aquém do que seria esperado. Dentre os inúmeros motivos que podem justificar tal desempenho, certamente aqueles afetos aos processos grupais estão demasiadamente presentes (CASTELLANI, 2010).

Perante esse quadro, a psicologia social pode trazer valiosas contribuições. Para Kurt Lewin, conforme destaca Mailhiot (1970), os objetivos da psicologia social são fornecer um diagnóstico sobre uma determinada situação social além de descobrir e formular a dinâmica própria da vida de um grupo sem, contudo, tratar desses dois objetivos de forma separada, dissociada e não complementar. Outra vertente é aquela defendida por PICHON-RIVIÈRE e Quiroga (1998) que procura "abordar o sujeito na interioridade dos seus vínculos, no seio das tramas de relação nas quais suas necessidades emergem, são decodificadas e significadas, cumprindo seu destino vincular e social de gratificação e frustração".

Apesar de reconhecer e compreender a demasiada importância dada ao rendimento e à necessidade de obtenção de bons resultados no futebol profissional, foram compartilhadas as proposições de RuBio (2003a, 2003b) por se entender que o fenômeno esportivo, neste caso específico o futebol, deva ser analisado em toda sua complexidade, não focando somente o rendimento e desempenho dos atletas e equipes, mas também a dinâmica das relações entre os agentes inseridos neste âmbito (dentre eles os atletas, comissão técnica, dirigentes esportivos, mídia, torcida, pesquisadores etc.), buscando situar o clube/equipe/atleta à realidade sociocultural em que vivem, tratando então a psicologia do esporte como a psicologia social do esporte.

\section{O caminho percorrido}

Este trabalho, seguindo as orientaçóes de uma pesquisa qualitativa e analítica, partiu da avaliação sistemática de um grupo de futebol com um recorte temporal específico. Foi efetuada a abordagem à equipe e aos atletas, possibilitando o desenvolvimento da pesquisa de campo ${ }^{1}$ com base em referenciais teóricos da psicologia social possibilitadores de leituras profundas e rigorosas da realidade, com as quais se tornaram possíveis a compreensão acerca dos processos grupais (sobretudo a liderança e a coesão grupal) e a análise da relação obtida entre o pesquisador e o clube, assim como o esclarecimento das dificuldades e facilidades encontradas pelo pesquisador.

Com a pretensão de atingir os objetivos propostos, foi selecionada uma equipe de expressão de futebol profissional do Estado de São Paulo. Entendemos como equipe de expressão aquela cuja história é marcada por conquistas, que possua boa representatividade junto à sociedade e que apresente uma estrutura física e administrativa de qualidade. Ainda assim, na necessidade de buscar dados mais palpáveis acerca dos clubes brasileiros, foram analisadas informações quantitativas que servissem como critério para escolha da instituição/clube/grupo a ser investigada. Dessa forma, foram buscadas em "rankings" divulgados em pesquisas recentes informaçóes que possibilitasse optar por uma instituição de expressão no cenário brasileiro. Dentre as informaçôes selecionadas nesses "rankings" estão as receitas brutas dos clubes e os resultados (partidas e campeonatos) obtidos por eles. Outro critério de escolha adotado passava pela conveniência em seu estudo, ou seja, preferencialmente o clube deveria localizar-se num local favorável ao pesquisador (portanto, no estado de São Paulo); quanto mais informaçōes e conhecimentos tivesse sobre ele, mais facilidade teria no seu estudo e, por fim, a existência de contato com alguém de dentro do clube traria maiores condiçōes para a realização da pesquisa.

Participaram da pesquisa atletas profissionais de futebol que estavam em atividade neste clube ${ }^{3}$, membros da comissão técnica e dirigentes desta equipe. A pesquisa de campo deu-se ao longo de 45 dias (com exceção dos dias em que os atletas estavam em partidas no campo do adversário fora da cidade de São Paulo). A proposta inicial era permanecer por no mínimo três semanas em contato diário com o clube pela necessidade e importância de "viver" e fazer parte do cotidiano de um grupo de jogadores profissionais 
de futebol interagindo com eles o maior tempo possível. Era necessário, então, vivenciar situações de jogo, treino, concentração, preleções e refeiçōes dos atletas, permitindo uma melhor e mais aprofundada leitura da realidade da qual eles fazem parte. Ainda assim, verificou-se a necessidade de uma aproximação maior, obtida por entrevistas com os funcionários do departamento de futebol (um diretor de futebol e um superintendente), alguns membros da comissão técnica (treinador, auxiliar técnico e preparador físico), e dois jogadores (dos quais somente um trouxe contribuiçốes relevantes para este estudo), com a finalidade de aprofundar e esclarecer os problemas e situações observadas. Entretanto, como esclarecido nas linhas que seguem, uma série de dificuldades prolongou a pesquisa de campo e limitou a presença em determinados ambientes e situações.

\section{Liderança e coesão grupal}

A liderança no futebol profissional tem ganhado cada vez maior atenção, preocupação e reconhecimento. Os atletas, alguns mais especificamente que outros, têm sido cobrados para exercerem esse papel com sabedoria e maestria, sendo um dos fatores inclusive preponderantes no momento de contratação e dispensa de jogadores. A esse respeito, valorizando, sobretudo, sua manifestação em momentos difíceis, um dos jogadores entrevistados emitiu a seguinte opinião:

Em todo segmento esportivo é importante ter o líder. Você ter um cara que tem essa liderança dentro de campo vai passar tranquilidade necessária pra que nós jogadores não tenhamos um abatimento naquela partida difícil e é por isso que é importante ter uma liderança dentro de campo. E fora de campo, pra dar tranquilidade pra aqueles que chegam ou pra aqueles que já estão há muito tempo, aquela conversa boa, de saber lidar com eles em situaçôes... Então o líder dentro de um segmento esportivo, principalmente dentro do futebol, é muito importante (jogador 1).

Reconheço neste estudo a grande importância e representatividade que possui a liderança para uma equipe de futebol. Neste ponto, em entrevista com o preparador físico da equipe estudada, pude observar o mesmo entendimento. Para ele:

É fundamental em qualquer instituiçāo, uma empresa, uma organização, uma família, as referências né, (ou as lideranças como você tá chamando), porque principalmente nos momentos difíceis essa
A observação participante, assim como propõe FONSECA (1999), esteve presente em vários momentos da pesquisa de campo a fim de captar a dimensão social das emoções dos sujeitos pertencentes ao grupo. Segundo ANDRÉ (1995), "a observação é chamada de participante porque parte do princípio de que o pesquisador tem sempre um grau de interação com a situação estudada, afetando-a e sendo por ela afetado". PICHON-RIVIÈRE (2000) vai além ao afirmar que "todo observador é sempre participante e modificador do campo de observação", criando uma situação de interação, uma unidade de relação dialética entre o sujeito e o objeto. Essa característica da observação participante foi notoriamente comprovada, visto que em diversos momentos a presença ou proximidade do pesquisador foi impedida e em outros, a convivência deu-se de modo mais próximo e informal.

referência é que vai ter o equilíbrio, é o que vai saber lidar com a situação, que não vai se apavorar, não vai se abater com as críticas, vai conseguir ver com clareza o que realmente tá acontecendo e como referência também de comportamento em relação ao treinamento, ao que se chama de profissionalismo, o que pra mim é obrigação, questão de horários né... Eu acho fundamental (preparador físico).

De acordo com Singer (1977), a liderança é entendida como uma relação de interação entre a personalidade do indivíduo e a situação, uma vez que toda situação requer talentos especiais para enfrentá-la e resolver os problemas que surgem dela. Por sua vez, Fiedler citado por SINGER (1977) afirma que a personalidade é de pouca importância na determinação do reconhecimento de um indivíduo como líder. Sugere que uma pessoa pode tornar-se um líder "estando no lugar certo na hora certa, ou devido a vários outros fatores como idade, educação, experiência, antecedentes familiares e saúde". No entanto, tal entendimento não é compartilhado por todos. Para LeITÃo (1999), por exemplo, o conceito de liderança pode também ser associado ao de personalidade, visto que o líder é entendido como o indivíduo que possui o maior número de traços desejáveis de personalidade e de caráter.

Neste ponto, o treinador entrevistado neste estudo, apesar de afirmar não existirem características predeterminadas de um líder, destinou à personalidade do sujeito significativa importância na sua postura e no seu comportamento de liderança. Vejamos: 
Eu não acredito que o líder tenha características predeterminadas. Acredito que nós não temos duas personalidades idênticas, então dessa forma não teremos nunca duas lideranças idênticas. Então as características eu não consigo entender... Eu acho que ele tem que agir normalmente de forma rápida e ter uma grande sensibilidade. Agora depende da personalidade desse líder. Aí cada líder vai ter a sua forma de agir, mas, individualizada... Totalmente relacionada à sua personalidade (treinador).

CARTWRight e Zander (1967), por sua vez, propõem que a liderança consiste em determinadas açôes, como estabelecer objetivos para o grupo e direcioná-lo a eles, melhorar a qualidade das interações entre os membros, desenvolver a coesão grupal, disponibilizar recursos aos integrantes, entre outras. Em outras palavras, a liderança consiste em contribuir de alguma maneira para alguma função do grupo. Ressaltam ainda que, em princípio, a liderança pode ser exercida por um ou vários membros do grupo.

Essa ressalva, por sinal, também foi constatada neste estudo por compreender que em um grupo de futebol a liderança não é exercida somente pelo treinador e capitão, como propõe Singer (1977). Corroboro com CARTwright e ZANDER (1967) ao afirmarem que "qualquer membro pode assumir certo grau de liderança, seja ou não indicado formalmente para uma posição ou um posto", e que demais funcionários e outros jogadores também exerçam, em suas devidas proporções, as funções de líder.

Facilmente foi identificado ao longo do período de convivência com o clube analisado que vários dos seus funcionários possuem e devem possuir características que os permitam assumir o papel/função de líder. Notoriamente, dentro do grupo de dirigentes existem aqueles profissionais que se destacam pela sua liderança. Da mesma forma, esse processo repete-se entre os funcionários da assessoria de imprensa, equipe médica, entre os membros da comissão técnica, e entre o grupo de jogadores. Entretanto, as diversas lideranças percebidas variam conforme o indivíduo que assume o papel de líder. Ou seja, dentro da comissão técnica há uma liderança nítida que é exercida pelo treinador. No entanto, quando analisados somente os preparadores físicos, outras lideranças emergem. $\mathrm{O}$ mesmo acontece na equipe de assessoria de imprensa e nos demais subgrupos. Mas vale ressaltar que, além de a presença de tais lideranças nos subgrupos não competirem com a liderança presente no grupo maior, nenhuma delas é igual a outra. Verifiquei, portanto, a existência de vários tipos de líderes.
A compreensão de que um grupo possa conter vários líderes nos remete à diferenciação apontada por CARTWRIGHT e ZANDER (1967) de variados tipos de líderes. Alguns deles são os lideres de opinião, aqueles capazes de influenciar as crenças e atitudes dos outros, os lideres socioemocionais, aqueles que possuem habilidades e recursos necessários para fazer com que os outros se sintam bem e satisfeitos com a participação no grupo, e, por fim, os líderes que estabelecem os objetivos pela sua facilidade em converter os interesses pessoais em objetivos de grupo. Dentro da comissão técnica, por exemplo, a liderança socioemocional, a de opinião e a da tarefa são desempenhadas por pessoas distintas, do mesmo modo como ocorre entre o grupo de atletas. Ou seja, enquanto um jogador se destaca por influenciar nas atitudes dos demais jogadores, outro toma a frente no estabelecimento dos objetivos do grupo e outro ainda proporciona um bom ambiente, fazendo com que todos se sintam bem e satisfeitos por fazer parte dele.

GIESENOW (2007), ao tratar da liderança em equipes esportivas, propôs a identificação de dois tipos distintos: o lider da tarefa e o lider socioemocional. Tal autor sugere que, enquanto o primeiro se caracteriza por ser o líder de jogo - altamente voltado para tarefa, com habilidades estratégicas e grande capacidade para tomar decisóes acertadas, dirigindo, iniciando e subordinando as atividades de grupo -, o segundo, o socioemocional, ou orientado para a pessoa, como propóe Fiedler citado por SAMULSKI (1992), é o líder das relações sociais, com alta capacidade para empatia, e que, com uma personalidade amistosa, apoia e ressalta os aspectos positivos dos companheiros de equipe. Assim, diminui os atritos existentes e contribui para criar um clima positivo dentro do grupo. Fiedler citado por SAMULSKI (1992) contribui ainda ao afirmar que ninguém está apto a mostrar que tipo de líder é superior ou mais efetivo, pois demonstra que cada um deles é bem-sucedido em certas situações, mas não em outras.

Em seu discurso, o superintendente técnico de futebol do clube analisado retrata de certa forma a existência dos líderes apontados por GIESENOW (2007). Vejamos:

Às vezes ele é líder porque tem que tem uma bola fantástica... Ele joga tanto que passa a ser encarado como líder pela efetividade, pelo talento, pela beleza do jogo, pela importância dele dentro de campo e às vezes pessoalmente ele não é (superintendente técnico de futebol).

Neste aspecto, o preparador físico da equipe analisada emite a seguinte opinião a respeito dos diversos líderes existentes numa equipe de futebol: 
Existe aqueles que são os líderes naturais, que tem um carisma, além de uma grande capacidade de entender o futebol, né, no aspecto tático, no aspecto grupal. Existem aqueles líderes calados, mas que pela sua atitude dentro do campo, pelo seu comportamento no dia a dia são admirados, são respeitados... Aquele que tem uma liderança porque o atleta é aglutinador, pelo seu bom humor, pela sua forma de descontrair o grupo, de aproximar todo mundo. Então, não há um único modelo. O legal é quando você consegue ter, de repente, no seu grupo, três, quatro atletas líderes de forma diferente. (preparador físico).

Semelhantemente, o superintendente técnico de futebol entrevistado aponta três tipos de liderança no futebol: uma que ele denomina liderança escondida ou silenciosa, ou seja, aquela em que o sujeito aborda tudo sem grande expressão de visibilidade, na qual ele tem grande participação nas atividades do grupo e sua ausência é super sentida, embora a sua visibilidade seja pequena; outra, a liderança técnica, que se caracteriza por ser a forma de representação do jogo se apropriando da linguagem verbal: ele lidera pelo que joga; e, por fim, a liderança efetiva, de imposição, de comando dentro de campo.

Entendo, assim como explicitado por ambos entrevistados, que num grupo de futebol existem diversas formas de exercer a liderança. Entretanto, é preciso ressaltar que, apesar de coexistirem variadas maneiras de a liderança se manifestar, elas se configuram na pessoa de dois líderes específicos, tratados por GIESENOW (2007) como o líder da tarefa e o socioemocional.

Independente da figura de quem a liderança esteja representada, o líder é, de acordo com Noce (1992), aquele que coordena os processos de interaçóes e comunicações existentes dentro do fenômeno da liderança. Este deve ser eficaz na transmissão de mensagens e apresentar boa capacidade de solucionar problemas e tomar decisões apropriadas. Duas formas de liderança poderão ser desempenhadas por este líder: a primeira, autoritária, definida como exclusiva competência na determinação dos objetivos a serem atingidos pelo grupo, promovendo total exclusão dos liderados quanto a qualquer tipo de participação na discussão e fixação deles. A segunda, democrática, na qual há preocupação em incorporar os próprios liderados nas tarefas de direção, distribuindo responsabilidades, incentivando por outro lado a intensificação dos processos interativos entre todos os integrantes da coletividade. De acordo com Eberspaecher citado por Noce (1992), o líder democrático estimula o grupo sob sua liderança com perguntas importantes e problemas permanentes em discussão. Ele descreve os passos possíveis para o alcance das metas, sugere alternativas e oferece ajuda. Por sua vez, conforme Noce (1992), o líder autoritário reveste-se de poder absoluto e absorve inteiramente a iniciativa do grupo, polarizando na sua pessoa a capacidade de planejar, decidir e controlar todas as açôes dos liderados.

White e LippiTT (1967), além de acrescentarem algumas características das formas de liderança autocrática e democrática, propõem ainda a existência de um terceiro estilo de liderança: o "laissez-faire”. A grande liberdade para que o grupo tome as decisóes e a participação mínima do líder são características fundamentais desse estilo.

Mais recentemente, alguns autores têm se apropriado do modelo de liderança situacional. NOCE (2002), por exemplo, enfatiza que este modelo foi criado com a intenção de "ajustar o comportamento do líder em função das características do grupo e da situação". Isso se justifica pelo entendimento de que o líder deve ter a capacidade de modificar seu estilo de liderança conforme uma série de variáveis. Desse modo, trabalha com três componentes essenciais: um que se refere à quantidade de orientação e direção oferecida pelo líder, denominado comportamento da tarefa; outro que se refere à quantidade de apoio socioemocional proporcionado pelo líder, denominado comportamento de relacionamento; e por fim aquele indicado pelo nível de prontidão dos subordinados, denominado pelo autor de maturidade do subordinado. É a este estilo de liderança que direciono minha maior afinidade neste estudo.

Neste ponto, em entrevista com o treinador da equipe analisada, facilmente pude identificar no seu discurso a valorização de alguns aspectos do comportamento do líder que se contemplam ao estilo de liderança situacional. Vejamos:

[...] vou liderar de forma diferente, dependendo da minha leitura em relação ao grupo e ao que vive o grupo naquele determinado momento. Isso na minha cabeça não tem também uma forma de liderar. Eu acho que tenho que ter várias ferramentas pra poder agir e de forma rápida (treinador).

Entretanto, apesar de reconhecer neste estudo a liderança situacional como a mais pertinente ao contexto do futebol profissional, podemos observar no discurso do preparador físico da equipe analisada a preferência por características no modo de estabelecer vínculo, relacionar-se com o grupo e adotar um comportamento de liderança que estão mais contempladas no perfil de um líder democrático. Em suas palavras: 
A forma que eu mais gosto é a de trabalho em equipe, do diálogo, do olho no olho... Se tem alguma coisa pra ser conversada tanto entre a comissão técnica quanto atleta, que seja de uma forma saudável e que as coisas sejam mais claras (preparador físico).

Ao explicitarmos a relação entre a liderança e a produção/rendimento do seu grupo/equipe, é preciso termos claro que esta não se dá de forma direta e mecânica. Concordo com MACHADO (2008), visto que, para ele, a liderança apresenta extrema importância para os profissionais que orientam grupos sociais na busca do máximo empenho e dedicação para conquista de metas. Entretanto, salienta que nem sempre a liderança, por si só, está condicionada a essa eficiência.

A equipe analisada neste estudo apresentou nos últimos anos grandes resultados, culminando inclusive com a conquista do tricampeonato nacional. Para um dos membros da comissão técnica entrevistado, além das excelentes condições de trabalho de que os funcionários do clube dispõem, a presença de uma liderança específica exercida por um determinado atleta é fundamental para os resultados atingidos.

[...] aqui já se tem um grande líder. Ele é o nosso grande diferencial!... É a pessoa que orienta dentro e fora de campo, que sabe tudo o que acontece com o clube e aquilo que se passa na outra equipe também (auxiliar técnico).

O papel do líder esportivo será então buscar estratégias para tornar a vida do grupo harmoniosa e atingir o estado de coesão, fundamental para motivar seus liderados a conquistar melhores resultados (BRANDÃo, 2000).

Semelhantemente, em entrevista com o treinador da equipe analisada, se observa a sua compreensão de que a liderança no futebol possui especificidades que quase sempre estão vinculadas ao rendimento esportivo. Ou seja, para ele:

A liderança tem que ter credibilidade. No nosso caso (o futebol profissional), ela está totalmente voltada ao rendimento técnico do líder sendo ele um jogador. Sendo ele da comissão técnica, também está diretamente relacionada aos seus resultados. A liderança vai ser positiva com os resultados... É evidente que numa fase difícil ela vai aparecer também, só que tem que estar credibilizada pelos resultados esportivos. É fundamental! (treinador).

Entretanto, o preparador físico demonstrou certa preferência pela liderança que é reconhecida (ou imposta, segundo ele) não pelos resultados obtidos, mas sim pela sua experiência, formação e conhecimento. Vejamos:
Há várias maneiras de você se impor. Alguns técnicos se impõem com conhecimento, por terem jogado, alguns por terem formação desportiva ou uma educação física ou curso, por intuição, por uma série de aspectos. Eu acho que o profissional tem que se impor exatamente dessa forma. Inconscientemente alguns, às vezes, se impõem pelo autoritarismo, pela arrogância, por uma forma de tratamento diretamente relacionada aos resultados, né... Eu não concordo muito com isso. Evidentemente que as pessoas que agem da primeira forma que eu coloquei têm uma longevidade maior, conseguem melhores resultados, mas aprendi também ao longo desses anos que há varias maneiras de se ganhar título, de se ganhar campeonatos (preparador físico).

Conforme LEWIN (1973), a organização de um grupo autocrático está baseada nas ações do líder. É ele quem determina a orientação e estabelece os objetivos para os membros do grupo. O campo de força desse líder irá manter o indivíduo em ação e fará do grupo uma unidade organizada. Por sua vez, no grupo democrático, todos os membros participam na determinação da sua orientação e traçam os planos e objetivos em conjunto. Dessa forma, cada membro irá possuir uma maior "mentalidade grupal” e seu grupo prosseguirá com sua própria força independentemente da presença do líder. Ser um líder nesse tipo de atmosfera significa "jogar limpo" e reconhecer as diferenças de opinióes e capacidades. Já o grupo de "laissez-faire”, no qual o líder se abstém no momento da intervenção, da ação, irá demonstrar poucos sinais de planejamento e trabalho grupal ou projetos individuais de longo alcance.

A atmosfera criada pelo líder da equipe que me propus analisar engloba as três orientações supracitadas (democrática, autocrática e "laissez-faire"), sendo possível verificar todas elas em um mesmo treino. Ou seja, durante as observações realizadas no Centro de Treinamento - local onde estive mais presente e próximo ao grupo -, em um mesmo dia pude verificar que, de acordo com a fase/período ou objetivo dos exercícios propostos, foi estabelecida uma atmosfera grupal específica. Conforme o momento do treinamento ou exercício proposto, o treinador tomava para ele a função de orientar e estabelecer todos os objetivos do grupo (caracterizando a atmosfera autocrática), ou dava aos atletas (e nesse momento ficava nítida a liderança de determinados jogadores) a possibilidade de participar da orientação e delimitação de objetivos (assim como em uma atmosfera democrática), ou ainda, como observei em quase todos os "rachôes", se abstinha 
totalmente da intervenção, caracterizando desse modo a atmosfera "laissez-faire". O estilo de liderança adotado e preferido pelo treinador da equipe contribui decisivamente para essa configuração da atmosfera grupal (CASTELLANI, 2010).

Para LEWIN (1973), existem dados que comprovam que o comportamento de um grupo em situaçōes democráticas, autocráticas e de "laissez-faire" não provém de diferenças individuais e sim da atmosfera estabelecida. A criação de uma atmosfera democrática irá apresentar um maior "sentimento grupal" dos seus membros do que numa atmosfera autocrática. Tal sentimento irá favorecer a diminuição de conflitos e tensōes, visto que a disposição do sujeito para entender as opiniōes e os objetivos dos demais membros e discutir racionalmente os problemas pessoais irá levar a uma solução mais rápida dos conflitos. Segundo Allport (1973), Lewin considera a liderança fundamental para determinar-se a atmosfera de grupo. Em uma atmosfera conflituosa, é exigida do líder uma postura democrática e de competência e preparo.

No tocante a manter um grupo unido e caracterizar então a coesão grupal, Carron, Widmeyer e Brawley citados por Hernandez e Gomes (2002) a conceituaram como um processo dinâmico que está refletido na tendência de um grupo para a confiança e unidade na busca de suas metas e objetivos. Seus estudos possibilitaram também a identificação de quatro conceitos que estão correlacionados: integração grupal-tarefa, integraçāo grupal-social, atração individual pelo grupo-tarefa e atração individual pelo grupo-social.

Semelhantemente, CarTwright e Zander (1967) também indicam três aspectos que são importantes ao descrever intuitivamente e operacionalmente a coesão de grupo. São eles: atração do grupo (o que inclui a resistência dos membros do grupo a deixá-lo); motivação dos membros para participar das atividades; e coordenação dos esforços dos participantes. Tais autores acreditam ser muito improvável que alguém consiga construir um único conceito que possua adequadamente esses três aspectos. Dessa forma, propõem limitar o conceito de coesão ao de atração de grupo, contudo, estando cientes da necessidade de utilizar diversos conceitos para descrever seus vários aspectos.

Algumas determinadas características do grupo, assim como seus objetivos, extensão, tipo de organização, entre outros e suas necessidades individuais que podem ser obtidas através do grupo, tais como a de afiliação, segurança e reconhecimento, são condiçôes que interferirão diretamente na atração do grupo (CARTWRight \& Zander, 1967). A lealdade ao grupo é um dos pontos que frequentemente está presente no discurso de autores que procuram conceituar e caracterizar um grupo coeso.

Algumas dessas características favorecedoras da coesão grupal são também valorizadas no futebol profissional, assim como nos aponta em entrevista o preparador físico da equipe investigada. Mesmo não abordando o conceito de coesão grupal em sua complexidade, ele diz que:

Da mesma forma pra um grupo de futebol, pra uma empresa, é importante que as pessoas se entendam e fundamental que se respeitem, não sendo necessário que se gostem... Se gostar melhor ainda, mas um grupo que tem harmonia, que se respeita e que se gosta, caminha melhor porque as ideias acabam combinando, a forma de pensar nos bons e nos maus momentos também. No bom momento a forma de se comportar é mais fácil, mas é importante sim que o companheiro sinta, por exemplo, uma crítica ao outro com se fosse a ele. Isso sim é companheirismo. Que o companheiro, sabendo que o outro não tá muito bem, ainda procure atuar mais e melhor pra suprir essa queda momentânea do companheiro, então eu acho que é sempre positivo, né, que haja esse entendimento (preparador físico).

Apesar de acreditar que não podemos estabelecer uma relação direta e pura entre a coesão de um grupo e seu rendimento, muitos autores propõem-se minimamente, e com as devidas ressalvas, realizar essa tarefa.

No discurso de um dos atletas entrevistados, ficou clara sua valorização pela coesão social e sua interferência no trabalho cotidiano e seu rendimento. Para o atleta:

O bom ambiente faz com que você tenha prazer em trabalhar e você tendo um ambiente aonde você tem prazer de estar aqui de manhã ou tarde, tem prazer de vir pra encontrar os companheiros de trabalho, isso com certeza é passado dentro de campo e acaba até em certos momentos difíceis da partida também lembrando que o ambiente é bom. Mas o ambiente só fica melhor quando você ganha, então, com certeza é o prazer de você estar trabalhando num lugar onde você tem pessoas que são queridas e pessoas que com certeza, queira ou não queira, indiretamente fazem parte da sua família (jogador 1).

Vários dos fatores levantados neste estudo como relevantes no processo grupal e, sobretudo, para a sua coesão, assim como a relação de interdependência entre os membros de um grupo de futebol, a presença de um líder, o estabelecimento de um bom 
ambiente, o apoio dos demais integrantes, entre outros, também foi ressaltado por um dos atletas entrevistados. $\mathrm{O}$ trabalho coletivo e a necessidade de uma sintonia quase que diária são fundamentais para a vida de um grupo de futebol.

Diariamente você precisa dos seus companheiros, da concentração de cada um deles, do desempenho, de um estímulo quando você não está bem estimulado e lógico que todo segmento esportivo, todo segmento que tem uma parte coletiva que seja importante, é importante você ter um bom ambiente e um líder pra que nos momentos bons e ruins você tenha aquele ponto estratégico, aquela pessoa que vai saber como conduzir (jogador 1).

Por fim, vale novamente enfatizar que a liderança e a coesão grupal no futebol profissional manifestavam-se em várias ocasiōes (nos treinamentos, nos momentos de descontração, situações de jogo e vestiário), ratificando sua importância e necessidade de maiores cuidados e preocupações. Há diversos indivíduos no grupo que possuem características para o desempenho de seu papel/função de líder devendo, entretanto, ser mais bem aprimoradas. Tais lideranças se configuram na pessoa de dois líderes específicos, tais quais o líder da tarefa e o socioemocional. Não necessariamente uma equipe possui ou deve possuir um único líder da tarefa e um único líder socioemocional. Ambos são demasiadamente importantes para o rendimento da equipe e principalmente para a qualidade e intensidade das relaçôes sociais existentes entre os membros do grupo, interferindo diretamente na coesão grupal desta equipe.

Por fim, vale novamente ressaltar que o estilo de liderança do treinador da equipe analisada aproxima-se daquela defendida neste estudo como a mais pertinente ao contexto do futebol profissional, denominada liderança situacional. Compreendida como estilo de liderança na qual o líder ajusta o seu comportamento e suas ações em função das características do grupo e da situação, este estilo é o preferido e adotado pelo treinador desta equipe, em virtude do discurso manifestado por ele em entrevista e pelas observações que foram possíveis de serem realizadas.

\section{A relação entre o pesquisador e o clube: limitações e obstáculos enfrentados}

A relação no papel de pesquisador com o clube se iniciou ainda num primeiro contato realizado por meio de correspondência eletrônica. No entanto, por mais que esse tenha sido o marco inicial da relação, ele ocorreu entre uma professora colaboradora do estudo e um dos diretores do clube, estando o pesquisador ainda longe do diálogo. Teve como finalidade pedir permissão para que o aluno/pesquisador tivesse acesso ao clube, permitindo a realização do estudo. Após o envio de algumas informaçôes a respeito dos objetivos e necessidades do aluno/ pesquisador, a resposta do dirigente foi positiva, ficando pendente somente um acordo sobre a data a ser iniciada a pesquisa. No entanto, vale ressaltar que do primeiro contato à autorização da realização da pesquisa, vários meses se passaram. A partir deste momento, por indicação do gerente de futebol, os contatos passaram a ser realizados diretamente com o assessor de imprensa do clube.

$\mathrm{O}$ assessor de imprensa do clube passou a partir de então a exercer um papel fundamental no relacionamento com o clube. No dia da primeira visita ao clube, após uma longa espera no portão do Centro de Treinamento (CT), fomos muito bem recebidos pelo assessor de imprensa. Conversamos sobre os objetivos e necessidades da pesquisa, acertamos uma data para minha volta ao CT e nos foi atribuído o papel de membro de imprensa. Isso mesmo, membro de imprensa. Ou seja, por alguns dias, teríamos o reconhecimento e acesso aos mesmos espaços e tempo permitidos às equipes de imprensa.

Aqui cabe a primeira reflexão. Por que será que a pessoa/funcionário responsável por nos receber foi o assessor de imprensa e não um dirigente ou algum membro da comissão técnica? Por que o papel abjudicado foi o de assessor de imprensa e não o de pesquisador? Qual seria o problema de ser apresentado como pesquisador e não como membro da imprensa? Por que esconder do grupo de atletas e comissão, por um tempo, o real motivo da nossa presença naquele ambiente (o CT)?

Uma hipótese para responder a tais perguntas passa pela preocupação do clube em saber os reais interesses da pesquisa, pelo desconhecimento do perfil e caráter do pesquisador, e pelo desejo de preservar o grupo de jogadores e comissão técnica de uma nova situação, a qual o próprio dirigente $\mathrm{e}$ o assessor de imprensa não tinham ciência de como 
se processaria. E dessa forma, pela necessidade de ter alguém que pudesse estar o mais próximo e num maior tempo possível nos acompanhando (ou vigiando), atento a todos os nossos movimentos, construíram essas condiçōes para desenvolvimento da pesquisa e encontraram na figura do assessor de imprensa a pessoa mais qualificada para esta tarefa de nos receber, acompanhar e dar suporte aos interesses da pesquisa. Ainda assim, mais próximos a ele, na condição fictícia de membro da imprensa, poderíamos ter acesso somente a espaços limitados e devidamente supervisionados por ele.

A partir do momento em que aceitamos (por não ver naquele momento outra opção) o papel de membro da imprensa, estabelecemos com o clube o que Pichon-Rivière (2000) define como vínculo e o entende como a "maneira particular pela qual cada indivíduo se relaciona com outro ou outros, criando uma estrutura particular a cada caso e cada momento".

Ao voltar no CT no dia combinado para dar início à pesquisa de campo, fomos novamente recebidos pelo assessor de imprensa. Estava claro que este foi o funcionário encarregado para ser o responsável por nos encaminhar aos espaços e ambientes necessários e dar apoio à realização da pesquisa, ou seja, a iniciativa de conversar com algum atleta, membro da comissão técnica ou de entrar em um determinado ambiente deveria ser por ele consentida.

Por alguns dias ainda encontramos dificuldades em entrar no CT, em nos aproximar do grupo de jogadores e comissão técnica e ainda nos identificavam como membro da imprensa. Fato que dificultava bastante a observação e coleta de informações conforme proposto metodologicamente.

A entrada no CT e aproximação ao campo e grupo de jogadores e comissão técnica só eram permitidas juntamente com os profissionais da imprensa. Apenas no quarto dia de visita pudemos, pela primeira vez, entrar no CT antes dos profissionais da imprensa. No entanto, momentos mais tarde, já com o treino iniciado, foi solicitado por um dos seguranças (provavelmente com a orientação da comissão técnica) que nos afastássemos do campo de visão do grupo. No dia seguinte fomos muito bem atendidos (embora após longa espera) pelo médico e superintendente técnico do clube, o qual nos concedeu entrevista para tratar de pontos específicos da pesquisa. Começava nesse momento a esclarecer aos demais funcionários do grupo nosso verdadeiro interesse (visto que até esse momento somente o diretor de futebol e o assessor de imprensa sabiam do motivo da nossa presença).
Essa rotina se repetiu por vários dias e aos poucos a entrada no CT e aproximação junto ao grupo eram cada vez mais fáceis de serem realizadas. Os seguranças passaram a nos reconhecer e facilitar a circulação pelo CT e os atletas e membros da comissão técnica a se acostumar com a nossa presença. Isso foi deveras importante, pois, além de suscitar uma possível mudança no papel nos designado, nos possibilitou presenciar os grupos e subgrupos que se formavam, as afinidades existentes entre eles, o ambiente/clima em situação anterior ao treino e principalmente realizar uma aproximação (cumprimentando e sendo cumprimentado por todos) junto aos atletas e comissão técnica.

Após alguns dias de contato com o grupo no centro de treinamento, foi obtida a primeira oportunidade de estarmos com o grupo em situações de jogo. Entretanto, tanto a entrada no Estádio, quanto a entrada no vestiário aconteciam de maneira muito dificultosa. A pretensão inicial de termos acesso ao vestiário antes e depois do jogo foi negada na maioria das vezes. Poderíamos levantar hipoteticamente algumas causas para esta impossibilidade, indo da não autorização da comissão técnica, da negativa do grupo de jogadores ou até pela opção do assessor de imprensa de nem mesmo verificar a possibilidade de tal observação se concretizar. A restrição quanto a entrada no vestiário com vistas a que pudéssemos vê-los chegar do campo de jogo analisando o comportamento do grupo, seus vínculos, a maneira de se relacionarem em situação de pós-jogo, enfim, que fosse possível ter acesso a todas as informações que possibilitariam atingir plenamente os objetivos de pesquisa, foi outro sinal percebido por nós de que teríamos dificuldades em observar e nos aproximar do grupo. Mais do que isso, nossa presença dentro do vestiário suscitou certa estranheza por parte dos jogadores e comissão técnica. Acredito que se sentiram incomodados com uma presença não habitual naquele ambiente, como se tivessem tido sua privacidade invadida e, não por coincidência, não mais nos foi permitido o acesso a este espaço. Começou a tomar forma então a compreensão de que a figura do pesquisador é estranha a este ambiente e que tal comportamento verificado ratifica o quão fechado é o grupo e o quanto eles procuraram se proteger de agentes externos.

Essa limitação foi um primeiro indicativo da impossibilidade de ter acesso a todos os aspectos referentes ao processo grupais de uma equipe profissional de futebol, principalmente aqueles que mais se relacionam com as intimidades pessoais e do grupo. Por outro lado, começaram a nos perceber 
não mais como membro da imprensa, mas também não ainda como pesquisador, e sim, provavelmente, como estagiário do clube.

No momento em que havíamos realizado aproximadamente metade das visitas ao clube, ainda era proibida a entrada em alguns ambientes do centro de treinamento (o interior da concentração e refeitório e também na piscina de hidroginástica) assim como a maior aproximação ao grupo de jogadores e comissão técnica. No entanto, no dia a dia, éramos muito bem tratados pelos funcionários, pelos membros da comissão técnica e pelo grupo de jogadores. Aos poucos o papel de membro da imprensa adjudicado ia se modificando para o de aluno/pesquisador. Inicialmente conseguimos entrevistar todos que julgávamos haver necessidade e fomos muito bem recebidos (salvo o longo tempo de espera em quase todas elas) por todos entrevistados. Por sinal, o elevado tempo de espera para ter acesso a determinados ambientes e observar como o grupo se comportava prejudicou demasiadamente a coleta de informações e as futuras análises. O tempo de espera para entrar no refeitório foi tão grande que quando autorizados a entrar, a maioria dos atletas já tinha terminado a sua refeição. O tempo de espera para entrar no vestiário antes e depois dos jogos, na maioria das vezes, foi tão grande que os atletas já estavam quase entrando em campo ou indo para o ônibus.

Nesta fase da pesquisa foi realizada uma nova conversa com o assessor de imprensa para programar a continuidade do estudo. Conversamos sobre a ida ao próximo jogo e necessidade de estarmos mais presentes e mais próximos do grupo nos vestiários, e também sobre a viabilidade de aplicação do teste de livre escolha. Ambas as necessidades metodológicas não puderam se concretizar visto que tanto nossa presença nos vestiários no próximo jogo, quanto a aplicação do teste não foram autorizadas. Segundo o assessor de imprensa, lhe foi dito (não explicitando por quem) que poderíamos ir ao jogo, mas sem a permissão de entrarmos no vestiário com a justificativa de que já teriam feito muito por nós e já tínhamos informações suficientes. Em relação à aplicação do teste, na opinião do assessor, esta tarefa seria muito difícil de ser realizada, visto que os atletas não possuíam o hábito de se comprometerem com este tipo de atividade. De fato, após entrevista com o preparador físico da equipe, este não viu viabilidade para sua execução por diversos motivos dentre os quais estão a dificuldade dos atletas em lidar com esse tipo de instrumento, a não abertura de suas intimidades, o receio de se exporem e o comprometimento ético (ao ter que citar colegas). Segundo ele, se fizéssemos parte da equipe, fossemos contratados pelo clube e estivéssemos no grupo há um bom tempo, a viabilidade de aplicação desse teste seria maior.

Tanto a negativa de nossa presença nos vestiários, mas principalmente as justificativas utilizadas por eles, carecem ser analisadas. Notoriamente, como explicitado anteriormente, nossa presença no vestiário foi percebida pelos jogadores e comissão técnica com certo incômodo e muito provavelmente tenha partido deles (mais provavelmente da comissão técnica) a opção por não mais nos permitir entrar naquele ambiente. Mais do que isso, pelo discurso adotado, fica clara a relação que detinham com o estudo e com o pesquisador, ou seja, uma relação muito mais de prestação de favor do que de interesse no estudo e nos resultados que ele poderia trazer.

Um dos fatores determinantes para a ampliação do período de pesquisa de campo foi a ausência de um dos atletas mais importantes no tocante aos processos grupais. Dessa forma, em concordância com o assessor de imprensa, esperamos a sua volta a fim de realizar as observações que vínhamos fazendo, agora com a sua presença. No entanto, a tão esperada entrevista com esse atleta não pode ser realizada. Ele é um dos poucos que possui uma assessoria de imprensa própria e, conforme nos afirmou o assessor do clube, é o jogador mais requisitado pela mídia, por patrocinadores, publicitários e pelos visitantes. Não ficou claro se a negativa de entrevista com ele partiu, portanto, do próprio atleta, da sua assessoria de imprensa ou do assessor do clube, que, ciente da dificuldade/trabalho que teria para autorizar a entrevista, principalmente pela limitada interferência que possuía na conduta dos atletas (e neste atleta especificamente), não fez sequer um contato para verificar essa possibilidade.

Deste modo, todas as informações e acessos aos ambientes e situaçóes que tivemos pareceram estar sob total controle do clube e esta negativa evidenciou que era intenção deles que permanecesse desta forma. Entendemos que tal iniciativa tenha partido com a nítida finalidade de preservar o grupo de qualquer fator que pudesse perturbá-lo (e claro, prejudicar seu rendimento) assim como colocar em risco os interesses do clube. Apesar de caminhar na contramão da pesquisa, essa postura do clube é compreensível, principalmente se refletirmos sobre as características do futebol contemporâneo.

Finalizada a pesquisa de campo permaneceu o entendimento de que a abertura dada para a realização 
da pesquisa, assim como as observações realizadas, o convívio diário em alguns ambientes do grupo e as entrevistas, apesar de terem sido bastante importantes para este estudo, foram insuficientes para compreender em sua totalidade os processos grupais de uma equipe de futebol profissional.

Apesar de estarmos com o grupo de atletas e comissão técnica em vários dos ambientes e situações em que os processos grupais se manifestam, nossa presença e circulação pelos espaços do clube foi impedida e/ou dificultada por diversas vezes. Pudemos sim observá-los nos treinamentos de campo, no REFFIS (Centro de Reabilitação Esportiva Fisioterápica e Fisiológica) e na piscina de hidroginástica. No entanto, em vários momentos fomos orientados a nos afastar do campo de visão do grupo, principalmente quando o treinador realizava reuniōes com os atletas. Da mesma forma também pudemos estar com o grupo em situações de jogo e vestiário. Porém, nunca no intervalo do jogo, quando chegavam ao estádio e se preparavam para o inicio da partida ou no momento em que retornavam do campo depois de finalizado o jogo. Dentro da concentração, a circulação era extremamente limitada. As situações de refeições somente puderam ser observadas na companhia do assessor de imprensa e sem a presença de todos os jogadores. Essas resistências não aconteceram por acaso, nem por interesse de uma única pessoa. Nitidamente se trata, além de questóes que perpassam o contexto de uma pesquisa que se propõe a conhecer os processos grupais, sobretudo o de coesão, de uma particularidade institucional. Ou seja, por atender aos interesses da instituição, momentos e situações foram propositalmente preservados fora do alcance do pesquisador justamente para delimitar a barreira entre o que pode e o que não pode ser observado, principalmente a fim de preservar o grupo de qualquer agente externo que possa colocar em risco o rendimento da equipe e o consequente interesse do clube (vitórias, títulos e o retorno que isso trará à instituição). Neste aspecto admitimos termos, por um lado, superestimado a possibilidade de inserção no grupo pesquisado e, por outro, subestimado a capacidade da instituição de preservar-se diante de sujeito estranho a ela.

Uma equipe dotada de uma história repleta de conquistas, com grande representatividade no cenário nacional e internacional, capaz de movimentar uma elevada quantia de dinheiro e cerceada por interesses políticos, mercadológicos e financeiros, dificilmente iria se expor a ponto de colocar em risco qualquer um destes aspectos e comprometê-los minimamente que seja. Entretanto, não queremos com isso dizer que as equipes de menor expressão apresentem maiores facilidades ao pesquisador, principalmente quando se tratar de conhecer, compreender e esclarecer as intimidades de um grupo e os seus processos grupais. De fato, os processos grupais, sobretudo a coesão de grupo, independente do contexto social ao qual estão inseridos, estão diretamente relacionados às diversas informaçôes sigilosas, que fazem parte única e exclusivamente de um determinado grupo, e portanto, cabe uma reflexão sobre até que ponto elas são passíveis de serem reveladas/divulgadas. Tal ponderação nos leva a supor que as restrições impostas pelo clube nesta pesquisa, seriam provavelmente também verificadas em outros grupos, sejam eles esportivos ou não.

Durante nossa convivência, os papéis adjudicados e assumidos foram sofrendo variações, mas não ao ponto de se configurar como vínculo ideal para o efetivo estudo dos processos grupais de uma equipe. Entendemos, em concordância com um dos membros entrevistados da comissão técnica do clube, que somente o estabelecimento de outro vínculo - que não de pesquisador acadêmico, muito menos o de estudante ou membro da imprensa - possibilitaria a aproximação ao grupo de tal forma que atletas e comissão técnica tivessem a devida confiança para se exporem e permitirem que todos os objetivos propostos fossem alcançados e toda metodologia contemplada. Ou seja, somente na condição de profissional do clube ou membro do grupo seria possível presenciar todas as situações de treino, jogo, preleção, concentração, enfim, estar com os atletas e comissão técnica nos ambientes em que se manifestam todos os processos grupais para analisá-los e compreendê-los de modo eficaz.

Uma possível saída encontrada para a sua realização seria então, na condição de pesquisador, assumir um vínculo distinto do assumido neste estudo associando os interesses da pesquisa aos do clube e não mais somente à ciência e ao contexto acadêmico ${ }^{4}$. Dessa forma, teríamos que ser requisitados e contratados pelo clube, e após passar por todos os momentos de introdução e aceitação no grupo, tais quais os de filiação, pertença, pertinência, comunicação, aprendizagem, tele e cooperação, sentirmos parte dele e ter, enfim, melhores condições para atingir plenamente os objetivos traçados neste estudo e cumprir com as exigências metodológicas propostas. Por outro lado é indispensável refletirmos e analisarmos sobre o que, de fato, propõe uma pesquisa acadêmica. Ou seja, dessa forma, os 
resultados obtidos seriam predominantemente, se não exclusivamente, de conhecimento do clube e não mais passível de serem publicizados, ao menos em relação aos interesses do clube, como se propõe uma pesquisa acadêmica?

Tal reflexão nos leva ainda a outra hipótese que deve ser considerada e relevada: A pesquisa seria desenvolvida/realizada por um membro do grupo, que estaria, sob esta configuração vincular, apto a buscar os objetivos pretendidos e decorrer sobre os resultados alcançados garantindo a divulgação daquilo que é de interesse acadêmico, no entanto, preservando as informações e "segredos" afetos somente ao grupo, garantindo o anonimato, se necessário torná-las públicas. De fato, configura-se como uma hipótese mais próxima da real possibilidade de pesquisa no futebol profissional, visto que é a que mais aproxima e faz coincidir os interesses do pesquisador e clube.

Reconhecemos, portanto, que, independentemente do clube analisado, as dificuldades para o estudo dos processos grupais em equipes profissionais de futebol provavelmente irão surgir e as limitações para a sua análise estarão presentes, variando, no entanto, conforme a grandeza e representatividade do clube, mas principalmente de acordo com o vínculo estabelecido entre o pesquisador e o clube/equipe.

Mesmo assim é possível concluir que todos os momentos e situações que pretendemos vivenciar, tais quais os espaços e situações de treinamento, ambiente de jogo, concentração, refeições, entre outros, devem ser observados e analisados quando se perspectivar compreender os processos grupais em uma equipe profissional de futebol.

A liderança e a coesão grupal manifestavam-se em várias ocasiōes (nos treinamentos, nos momentos de descontração, situações de jogo e vestiário), ratificando sua importância e necessidade de maiores cuidados e preocupaçôes. Há diversos indivíduos no grupo que possuem características para o desempenho de seu papel/função de líder devendo, entretanto, ser mais bem aprimoradas. Tais lideranças se configuram na pessoa de dois líderes específicos, tal qual o líder da tarefa e o socioemocional. Não necessariamente uma equipe possui ou deve possuir um único líder da tarefa e um único líder socioemocional. Ambos são demasiadamente importantes para o rendimento da equipe e principalmente para a qualidade e intensidade das relaçôes sociais existentes entre os membros do grupo, interferindo diretamente na coesão grupal desta equipe.

\section{Notas}

1. A pesquisa de campo foi realizada após o consentimento livre e esclarecido daqueles os quais nos propusemos observar/ entrevistar/analisar.

2.CASTELLANI, R.M. Em jogo a relação entre o pesquisador e clube: futebol e processos grupais. Dissertação (Mestrado em Educação Física) - Faculdade de Educação Física, Universidade Estadual de Campinas. Campinas, 2010.

3. O nome do clube será preservado em sigilo neste artigo para manter no aninomato a identidade do clube em publicações que não a dissertação, conforme acertado com o clube.

4. Não queremos com isso dizer que o clube não pode associar seus interesses aos da Ciência. Mas que, conforme já explicitado neste artigo, há informações sigilosas afetas somente ao grupo e que, portanto, devem permanecer, respeitando os interesses do clube, somente sob seu domínio, indo, dessa forma de encontro ao processo de divulgação/circulação do conhecimento, conforme pretendido e defendido pelo meio acadêmico.

5. Vale ressaltar que, um pesquisador que estivesse sob a configuração deste vínculo poderia atribuir à pesquisa de campo outro significado, visto que seu foco principal não seria mais o de buscar informações e se "familiarizar" com o grupo, mas o de tornar estranho algo que já lhe é peculiar. 


\begin{abstract}
Leadership and group cohesion in professional football: the off-game researcher

The aim of this study was to investigate the effects of leadership on the functioning of the group; detect the importance and necessity of cohesion in a professional team of footballers; describe/analyze the relationship between the researcher and club; and point the limitations and obstacles found during field research. Following the guidelines of qualitative research and having as a theoretical reference the field of social psychology, with emphasis on studies of Kurt Lewin and Pichon-Rivière, this research came from analysis of a professional football club. The main difficulties encountered were: impossibility of access to places or situations suggested as methodology; the denials for interviews; and rejection of the applicability of a free choice test. The bonds created and the roles taken harmed attempts of further analysis. Perception of the importance of leadership and group cohesion is present in professional football, with situational and democratic leadership being more relevant in that specific context.
\end{abstract}

UnITERMs: Research; Professional football; Group; Link; Social psychology.

\title{
Resumen
}

El liderazgo y cohesión del grupo en el fútbol profesional: el investigador fuera del juego

Parte de mi disertación de maestría, este artículo tiene como objetivo: retratar los efectos de liderazgo sobre el funcionamiento del grupo; detectar la importancia y la necesidad de un grupo cohesionado en el fútbol profesional; describir/analizar la relación entre el investigador y el club; y señalar las limitaciones y los obstáculos enfrentados durante la investigación de campo. De carácter cualitativo y con referencial teórico de la psicología social, en especial de Kurt Lewin y Pichon-Rivière, este estudio se basó en el análisis de un equipo de fútbol profesional. Entre las dificultades encontradas, se pueden destacar: imposibilidad de acceso a situaciones/locales sugeridos metodológicamente; negaciones a las entrevistas; el rechazo a la aplicabilidad del examen de libre elección. Se identificó la voluntad/necesidad del club en mantener tales limitaciones para el investigador. El vínculo creado y las funciones asumidas han dañado aún más los análisis. La percepción de la importancia acerca del liderazgo y de la cohesión del grupo está presente en el fútbol profesional, teniendo el liderazgo situacional y el democrático más grande relevancia en este contexto particular.

Palabras Clave: Investigación; Fútbol profesional; Grupo; Vínculo; Psicología social.

\section{Referências}

ALLPORT, G. Introdução. In: PROBLEMAS de dinâmica de grupo. 2. ed. São Paulo: Cultrix, 1973.

ANDRÉ, M.E. Etnografia da prática escolar. 10.ed. Campinas: Papirus, 1995.

BRANDÃO, R. Fatores de stress em jogadores de futebol profissional. 2000. Tese (Doutorado em Educação Física) Faculdade de Educação Física, Universidade Estadual de Campinas, Campinas, 2000.

CARTWRIGHT, D.; ZANDER, A. Dinâmica de grupo: pesquisa e teoria. São Paulo: Herder, 1967.

CASTELLANI, R. Em jogo a relação entre pesquisador e clube: futebol e processos grupais. Dissertação (Mestrado em Educação Física) - Faculdade de Educação Física, Universidade Estadual de Campinas, Campinas, 2010.

ESCHER, T.; REIS, H. As relações entre futebol globalizado e nacionalismo: o exemplo da Copa do Mudo de 2006.

Revista Brasileira de Ciências do Esporte, Campinas, v.30, n.1, p.41-55, 2008. 
FONSECA, C. Quando cada caso não é um caso: pesquisa etnográfica em educação. Revista Brasileira de Educação, Rio de Janeiro, n.10, p.58-78, 1999.

GIESENOW, C. Psicologia de los equipos deportivos: claves para formar equipos exitosos. Buenos Aires: Claridad, 2007. LEITÃO, J.C. A relação treinador-atleta: percepção dos comportamentos de liderança e de coesão em equipes de futebol. 1999. Tese (Doutorado) - Faculdade de Ciências do Desporto e Educação Física, Universidade de Coimbra, Coimbra, 1999. LEWIN, K. Problemas de dinâmica de grupo. 2. ed. São Paulo: Cultrix, 1973.

. Teoria de campo em ciência social. São Paulo: Pioneira, 1965.

LOVISOLO, H. Saudoso futebol, futebol querido: a ideologia da denúncia. In: HELAL, R.; SOARES, A.; LOVISOLO, H. A invenção do país do futebol: mídia, raça e idolatria. Rio de Janeiro: Mauad, 2001.

HERNANDEZ, J.A.E.; GOMES, M.M. Coesão grupal, ansiedade pré-competitiva e o resultado dos jogos em equipes de futsal. Revista Brasileira de Ciências de Esporte, Campinas, v.24, n.1, p.139-50, 2002.

MACHADO, A. Liderança: novas perspectivas no futebol. In: BRANDÃO, R. et al. Coleção psicologia do esporte e do exercício. São Paulo: Atheneu, 2008. v.3.

MAILHIOT, G.B. Dinâmica e gênese dos grupos: atualidades das descobertas de Kurt Lewin. São Paulo: Duas Cidades, 1970. NOCE, F. Liderança. In: SAMULSKI, D. Psicologia do esporte. Belo Horizonte: Manole, 1992.

PICHON-RIVIÈRE, E. O processo grupal. São Paulo: Martins Fontes, 1982.

Teoria do vínculo. 6. ed. São Paulo: Martins Fontes, 2000.

PICHON-RIVIÈRE, E.; QUIROGA, A. P. Psicologia da vida cotidiana. São Paulo: Martins Fontes, 1998.

REBELO, A.; TORRES, S. CBF-Nike. São Paulo: Casa Amarela, 2001.

REIS, H. Futebol e sociedade: uma análise histórica. Revista Histedbr On-line, Campinas, n.10, 2003. Disponível em: $<$ http://www.histedbr.fae.unicamp.br/revista/revis/revis10/rev10.html>.

REIS, H.; ESCHER, T. Futebol e sociedade. Brasília: Liber Livros, 2006.

RUBIO, K. Estrutura e dinâmica dos grupos esportivos. In: (Org.). Psicologia do esporte: teoria e prática. São

Paulo: Casa do Psicólogo, 2003a.

Psicologia do esporte aplicada. São Paulo: Casa do Psicólogo, 2003b.

SAMULSKI, D. Psicologia do esporte. Belo Horizonte: Manole, 2002.

SINGER, R.N. Psicologia dos esportes: mitos e verdades. 2. ed. São Paulo: Editora, 1977.

SMIT, B. Invasão de campo: Adidas, Puma e os bastidores do esporte moderno. Rio de Janeiro: Jorge Zahar, 2007.

WHITE, R.; LIPPITT, R. Comportamento do líder e reação dos membros em três "climas sociais". In: CARTEWRIGHT, D.; ZANDER, A. Dinâmica de grupo: pesquisa e teoria. São Paulo: Herder, 1967.

\begin{tabular}{r|l} 
ENDEREÇO & \\
Rafael Moreno Castellani & Recebido para publicação: 08/06/2011 \\
R. Angela Buziolli Tonon, 47 & Revisado: 07/05/2012 \\
13140-000 - Paulínia - SP - BRASIL & Aceito: 25/05/2012 \\
e-mail: rafael.moreno@uol.com.br & \\
&
\end{tabular}

